KOMPASS

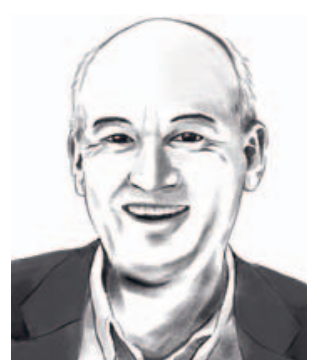

Harald Walach

Poznan/Berlin,

Polen/Deutschland

Ich stelle bei Vorträgen gerne eine Frage, die auch die meisten Ärztinnen und Ärzte nicht auf Anhieb richtig beantworten: «Was ist diejenige medizinische Intervention, die am meisten Leben gerettet hat?» Meistens sagen die Leute: «Antibiotika» oder «Impfungen». Falsch! Richtig ist Hygiene. Als Rudolf Virchow um 1850 Schlesien bereiste und zurückkam mit der Empfehlung, Hygiene flächendeckend einzuführen und damit Medizin zu einem Mittel der Politik zu machen, legte er den Grundstein für die profundeste Revolution in der Medizingeschichte. Thomas McKeown stellte bereits 1976 fest: Die großen Infektionskrankheiten und Epidemien - Tuberkulose, Keuchhusten, Tetanus, Diphtherie, Cholera und Typhus - waren schon längst auf dem Rückzug, bevor Impfungen aufkamen [1]. Er führte das auf die Hygiene und den verbesserten allgemeinen Ernährungszustand zurück.

Seither ist Hygiene in der westlichen Welt eine Selbstverständlichkeit geworden, vielleicht manchmal schon zu sehr. Darauf hat mein alter Chef am Institut für Umweltmedizin und Krankenhaushygiene der Freiburger Uniklinik Franz Daschner immer hingewiesen, der Flächendesinfektion und Antibiotika für die Zunahme von Resistenzen verantwortlich machte. Das ist gewissermaßen die Dialektik des Fortschritts, aber das nur am Rande.

Diese Selbstverständlichkeit hält den westlichen Menschen im Durchschnitt 30 bis 60

\title{
Hygienerevolution des Geistes
}

\section{Harald Walach}

Poznan/Berlin, Polen/Deutschland
Minuten pro Tag im Badezimmer. Darum können wir auch einigermaßen unbelästigt von Gerüchen unangenehmer Art in einem Zug oder einer Straßenbahn fahren.

\section{Zähneputzen fürs Gehirn}

Nun ist unser Körper hygienisch rein, wie steht es aber um unser Innenleben? Ich meine, eine neue Revolution steht an, die mit der Hygienerevolution vergleichbar ist: allgemeine geistige Hygiene. Wenn sich jemand nicht wäscht, riecht man das, jedenfalls nach ein bis zwei Tagen. Wenn jemand seinen Geist nicht putzt, riechen wir das dummerweise nicht nicht mal bei uns selbst! Nun ist unser Geist aber mindestens ebenso wichtig wie der Körper, und, wie uns die Psychosomatik gelehrt hat, nicht selten auch Quell heikler körperlicher Probleme, aber auf jeden Fall Grund gesellschaftlicher Übel. Eine Hygiene des Geistes würde vermutlich genauso weitreichende Effekte haben wie Virchows physische Hygienerevolution. Die alte Pali-Sprache hat dafür sogar einen technischen Begriff: dhyana. Die ersten deutschen Indologen übersetzten das mit Meditation. Aber eigentlich heißt der Begriff Kultur des Bewusstseins oder Kultivierung des Geistes [2]. Damit ist gemeint: Genauso wie um unseren Körper und seine Reinlichkeit sollten wir uns um unseren Geist bemühen. Durch tägliches Saubermachen. Meditation, also ca. 20 bis 30 Minu- ten nichts tun, außer den Geist vom Gerümpel unnützer Gedankenaktivität entleeren, ist eine wichtige Komponente. Sich ein bisschen beim geistigen Kragen nehmen und unkonstruktive Gedankenschleifen abbrechen sowie zielführende innere Bilder und Gedanken kultivieren ist ein weiterer Aspekt. Und gerade heutzutage vielleicht zentral: sich der Flut unnützer und ablenkender Bilder und Informationen entziehen - Bilder- und Informationsfasten könnte man sagen -, um der Zerstreuung Einhalt zu gebieten. Dafür müssen wir lernen, unseren Geist zu lenken. Das ist schwieriger, als man denkt. Daher ist eine tägliche Meditationsübung die Basis. «Zähneputzen fürs Gehirn», nenne ich das gern.

Nicht auszudenken, wohin das führen würde, wenn sich geistige Hygiene genauso verbreiten würde wie die körperliche. Vielleicht könnten wir ein paar noch gefährlichere Epidemien als Cholera in den Griff kriegen: Depression und Erschöpfung? Gier nach noch mehr? Unzufriedenheit und Sinnentleerung? Gewalt und Ausgrenzung? Es ist leicht, die anderen für das Chaos verantwortlich zu machen. Es ist sehr schwer, bei sich selbst den ersten Keim der Veränderung zu legen. Aber genauso hat Virchow mit der Hygienerevolution begonnen.

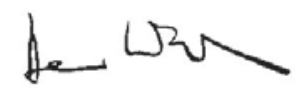

Prof. Dr. Dr. phil. Harald Walach

\section{Literatur}

1 McKeown T: Die Bedeutung der Medizin: Traum, Trugbild oder Nemesis? Frankfurt/M., Suhrkamp, 1982.
2 Metzinger T: Der Begriff einer «Bewusstseinskultur». E-Journal Philosophie der Psychologie 2006;4.

\section{KARGER}

Fax +497614520714

information@karger.com

www.karger.com

\section{(c) 2018 S. Karger GmbH, Freiburg}

Accessible online at:

www.karger.com/kkd
Prof. Dr. Dr. phil. Harald Walach

CHS Institut

Schönwalder Straße 17

13347 Berlin, Deutschland 